Javanmardi, A., Zhang, Y.X., Liu, Y.C., Yang, S.J., Yu, X.X., Liu, M., and Hsiang, S.M. (2019). "Manager Perception and Decision for Making-do in China vs. the U.S." In: Proc. $27^{\text {th }}$ Annual Conference of the International. Group for Lean Construction (IGLC), Pasquire C. and Hamzeh F.R. (ed.), Dublin, Ireland, pp. 1175-1186. DOI: https://doi.org/10.24928/2019/0255. Available at: 〈www.iglc.net>.

\title{
MANAGER PERCEPTION AND DECISION FOR MAKING-DO IN CHINA V.S. IN THE U.S.
}

\author{
Ashtad Javanmardi', YuXiang Zhang', YanChun Liu², ShuJuan Yang², XiuXia \\ $\mathbf{Y u}^{2}$, Min Liu ${ }^{*}$, Simon M. Hsiang ${ }^{3}$
}

\begin{abstract}
Making-do, a decision to start work despite knowing that preconditions are not fully ready, has been referred as a type of waste in construction projects. It will be interesting and beneficial to understand how project managers make making-do decisions when managing projects in different countries and cultures. This research conducted two surveys, one in China and one in the U.S., to study how making-do decision is made differently in two countries by project managers with various levels of experience and responsibility. The research also examined whether there is significant difference in experienced task starting time and duration variation between people with different making-do preference. Findings showed that there was a significant difference in making-do decision preference for construction managers in China vs. the U.S. However, there was no significant difference on making-do decision preference for managers at different responsibility levels. Results revealed Chinese managers who preferred making-do have experienced significantly higher duration variation while in U.S. the results are opposite. Emphasizing obedience, remaining consistency with peers and supervisors, and constantly checking labor, equipment, and materials availabilities are highly valued in the Chinese culture and management practice, which contributed to the making-do decision outcomes in China vs. the U.S. The findings help project managers to understand the difference and rationale in making-do decisions and have more efficient collaboration and communication when they work in projects located in a foreign country.
\end{abstract}

\section{KEYWORDS}

Making-do, lean construction, constraints, China, U.S.

\footnotetext{
North Carolina State University, Raleigh, NC 27695-7908, USA, Tel: 001-919-513-7920

2 Qingdao University of Technology, No 11 Fushun Road, Qingdao, Shandong, China, Tel: 0086-053285071060

3 University of North Carolina at Charlotte, Charlotte, NC 28223 -0001, USA, Tel: 001-704-687-1958

* Corresponding author. E-mail address: min_liu@ncsu.edu
} 


\section{INTRODUCTION}

Making-do refers to starting a task before all preconditions are ready (Koskela 2004). Making-do is a complex phenomenon and it is very difficult to avoid, because it is both rational and irrational decision at the same time (Bølviken and Koskela 2016). Although making-do is a locally and momentarily rational strategy to reduce waste, reasoning that "it is better to do something than to do nothing", in a long run it can be counterproductive from the perspective of the production system and results in waste (Bølviken and Koskela 2016).

Previous literature suggests different possible reasons for making-do, including high capacity utilization (Koskela 2004), getting the job (Koskela 2004), schedule compliance (Koskela et al. 2013), profit (Pikas et al. 2012), lack of trust (Formoso et al. 2011), and the false belief that "the sooner you start the sooner you finish" (Koskela 2004). However, there may be other possible factors influencing making-do decisions. For example, do people from different countries or culture background choose to use making-do differently? Do people with more experience prefer to wait when preconditions are not ready? Are higher-level managers more cautious than crew-level managers in deciding the timing to start a task? Do managers who prefer to choose making-do tend to experience shorter overall task delay?

In order to answer the above questions, this research conducted two surveys in China and the U.S. Both focus on government projects performed by civilian contractors. The survey in China was distributed among 16 government/public projects from June to August 2018 and collected 141 usable responses. The survey for the U.S was distributed among 240 construction companies working on government/public projects from July to August 2009 and collected 119 usable responses (Wambeke et al. 2011). Using the total 260 responses, the research conducted four hypothesis tests: $H-1$ : There is no association between making-do decision preferences and the country in which project managers are working. H-2: There is no association between making-do decision preferences and managers' level of construction experience. $H-3$ : There is no association between makingdo decision preferences and mangers' responsibility level. $H$-4: Project managers with different making-do preferences experience the same amount of task starting time (and duration) variation. In this research, task starting time variation is defined as the difference between the planned and actual task starting time. Task duration variation is the difference between the planned and actual task duration.

\section{LITERATURE REVIEW}

\section{MAKING-Do}

Making-do as a waste refers to a situation where a task is started without readiness of all its preconditions, or the execution of a task is continued although the readiness of at least one precondition has ceased (Koskela 2004). Preconditions included labor, material, equipment, detailed design and instructions, space, prerequisite work completion, and external condition (i.e. suitable weather) (Koskela 2000). Conceptually, making-do is the opposite of buffering. Whereas in buffering there is a positive waiting time for 
preconditions to get ready before starting a task, in making-do that waiting time is negative, (Koskela 2004). Koskela (2004) argued further that besides buffering, "making-do is another penalty due to variability" because it is practiced for maintaining a high utilization rate and/or for avoiding schedule slippage.

Formoso et al. (2011) stated that "making-do has a strong relationship with the concept of improvisation." This is because when people face difficult and uncertain situation, they tend to use whatever resources available to reach their objectives (Cunha 2004). Pikas et al. (2012) mentioned that making-do decisions can happen by the crew leaders (last planners) even after the crew has committed to the weekly work plan. They must decide whether to start the task at hand or to wait when conditions are different from those contemplated in the weekly work plan. There are numerous factors influence making-do decisions. For example, perception of the state of readiness, maturity of the work (Pikas et al. 2012), maintaining profitability by utilizing resources (Koskela 2004; Pikas et al. 2012), start the work just for getting the job (Koskela 2004), and lack of trust and pressure of an immediate response (Formoso et al. 2011; Koskela 2004). When choosing making-do, project managers believe that by starting early, even with lack of preconditions, the task will also be completed earlier (Koskela 2004).

By collecting data from two case studies and performing explanatory data analysis Formoso et al. (2011) found: (1) the most frequent types of making-do were related to the access and availability of working areas, temporary facilities, protection, and equipment and tools; (2) the main causes of making-do were the ineffectiveness in providing adequate temporary facilities, poor management of layout/space, and insufficient information; and (3) the main impacts were material waste, poor safety conditions, and reduced motivation. Pikas et al. (2012) collected empirical data over eleven weeks at a large residential construction project. They analysed different scenarios based on task go/no-go decisions and their outcomes and developed a flowchart of making-do decision-making process at operational level. Neve and Wandahl (2018) actively participated in weekly Last Planner System $\left(\right.$ LPS $^{\circledR}$ ) meetings and conducted work sampling studies on six trades for three housing refurbishment projects. They found that making-do is highly likely to be the prevailing reason for the low productivity in refurbishment projects. Furthermore, they found an apparent correlation between excessive talking and making-do, concluding that excessive talking is a valid making-do indicator (Neve and Wandahl 2018).

Although previous research has emphasized on the complexity of a making-do decision, suggested stimulating factors behind making-do decisions, and demonstrate the impact of making-do on project performance, it is still unclear whether culture background, level of experience, and responsibility have significant relationship with making-do decision. It will also be valuable to learn how making-do choice is associated with the amount of experienced task starting time and duration variation. Identifying the impacting factors will help project managers to understand how people with different culture background, responsibility level, and previous project experience react differently in the decisionmaking. It also will help project managers to have more efficient collaboration and communication when they work in projects located in a foreign country. 


\section{METHOD}

\section{QUESTIONNAIRE SURVEY}

The survey questionnaire was first designed in English and distributed to 240 civilian contractors performing public work under a government contract in 2009 (Wambeke et al. 2011). Those contractors and projects located throughout the U.S. The survey questionnaire was adjusted and translated into Chinese. The adjustments were made to change the expression of the terminologies commonly used and understandable in Chinese. The Chinese version was then translated back to English. The final version in English matched the original version in English. The Chinese survey was distributed to 16 projects located throughout ShanDong province in China in 2018. ShanDong is the most populous and third affluent provinces located in the north-east region in China. All projects were under a government contract and performed by civilian contractors.

Each survey contains three parts. The first part asked respondents' background information such as years of experience in construction, current position, etc. The second part asked whether respondents prefer to "start" a work or "wait" when the preconditions (labor, material, equipment, etc.) are not fully ready. In the third part, respondents were asked to state on average how many hours per week they have experienced task starting time (and duration) variation in their most recently completed project, due to the 50 preidentified causes of task variation. The 50 individual causes were listed in eight precondition categories. The eight precondition categories included Koskela's seven precondition categories (Koskela 2000) and an "information flow" category. Examples of the causes in "detailed design and instructions" precondition category are constructability issues in design, design changes, insufficient drawings before starting work, long owner's response time, long consultant's response time, vague and unclear drawings details, nonstandard and complex structure, and nonspecific construction method and instructions.

\section{SURVEY RESPONSE}

The research team received 214 responds from the survey in China and 260 responses from the survey in the U.S. A two-step approach was taken to clean the data and identify the usable responses. First, responses with less than $25 \%$ of questions answered was removed. Second, the three-times interquartile range $(3 \times \mathrm{IQR})$ was used as a cut-off point for removing outliers (Iglewicz and Hoaglin 1993). After data cleaning, 141 usable responses from China and 119 usable responses from the U.S. were identified.

\section{ANALYSIS AND RESULTS}

\section{H-1: There is no association between making-do decision preferences and the managers' country of origin (China or the U.S).}

A chi-square statistic test was conducted test the null hypothesis that the two categorical variables "Country" and "Making-do" are independent. A crosstabulation of country and making-do was created (Table1).

The chi-square $\left(\chi^{2}\right)$ was calculated by comparing the observed number and the expected number of using the following equation: 


$$
\chi^{2}=\sum_{\text {all cells }} \frac{(\text { observed }- \text { expected })^{2}}{\text { expected }}
$$

The value was $\chi^{2}=6.726$ and was significant at $\alpha=0.05$ level with the $p$-value of 0.011 . Therefore, the null hypothesis is rejected: there is a significant association between country and making-do.

Table 1: Crosstabulation between country and making-do

\begin{tabular}{ccccc}
\hline \multirow{2}{*}{ Country } & Count & \multicolumn{3}{c}{ Making-Do } \\
\cline { 3 - 5 } & & Yes & No & Total \\
\hline \multirow{3}{*}{ China } & Observed & 88 & 53 & 141 \\
& Expected & 95.4 & 45.6 & 141.0 \\
& \% Row & $62.4 \%$ & $37.6 \%$ & $100.0 \%$ \\
\hline \multirow{3}{*}{ U.S. } & Observed & 92 & 27 & 119 \\
& Expected & 82.4 & 36.6 & 119.0 \\
& \% Row & $77.3 \%$ & $22.7 \%$ & $100.0 \%$ \\
\hline \multirow{2}{*}{ Total } & Observed & 180 & 80 & 260 \\
& Expected & 180.0 & 80.0 & 260.0 \\
& \% Row & $69.2 \%$ & $30.8 \%$ & $100.0 \%$ \\
\hline
\end{tabular}

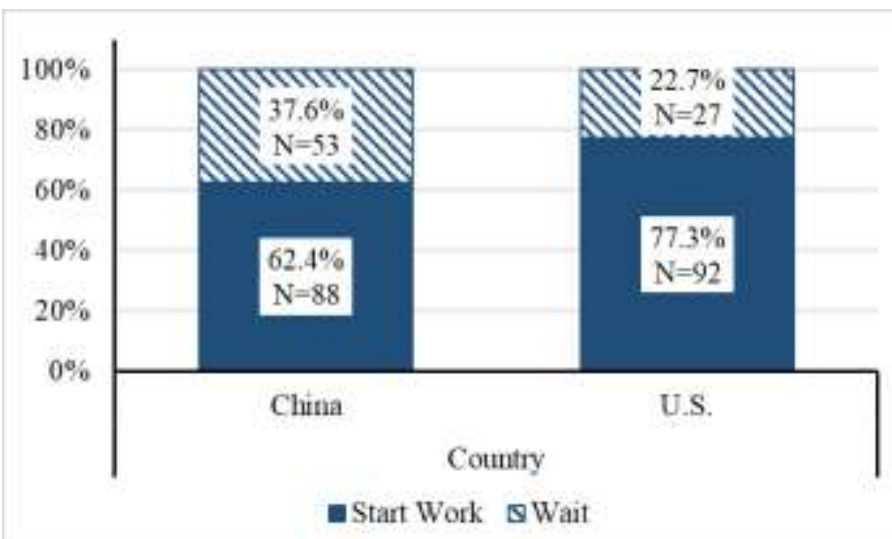

Figure 1: Making-do preference by country

Overall, as demonstrated in Figure 1, making-do is a more preferred choice for both China $(62.4 \%)$ and the U.S. (77.3\%). The research team interviewed five experienced project managers in China. They emphasized the importance of $n$ on-time completion of public projects duo to high visibility and potential politic influence. For example, the new QingDao International Airport, Sino-German EcoPark, and HuangDao Resettlement Housing projects. Therefore, the government gave high priority and timely support when 
there is any problem. The contactors also utilized their best long-term partners to provide labor, equipment, and materials. Another unique phenomenon in construction projects in China is that all workers and site managers stay on job site 24 hours per day for the entire duration of their portion of work. The workers are farmers from various regions in China. They learn construction work skills as a tradition in their villages and form groups to work on projects in cities. Labor dealers have contact with a larger number of those group leaders. Once there is a need from a construction project and an agreement on the work duration and price, labor dealers call group leaders to send workers on site. This can happen with a few phone calls or text messages and workers can show up in a few hours. Contractors provide food and board for workers and pay labor dealers directly. Labor dealers then pay group leaders after taking their profit. Site managers also stay on job site 24 hours per day for at least six days a week. Managers usually expect a short turnaround time get problems resolved when preconditions are not ready. This could be one of the reasons why managers in China are more likely decide to wait. They have the expectation that the waiting time won't be long.

\section{H-2: There is no association between making-do decision preferences and managers' level of construction experience.}

All usable responses were classified into three groups based on their experience in construction industry: (1) less than five years of experience, (2) five to ten years of experience, and (3) ten years of experience or more. The chi-square test was performed three times, for China, the U.S., and combined. None of the chi-squares were statistically significant, meaning that the null hypothesis is true: making-do decisions and the level of experience are independent (not related). Figure 2 shows that Chinese managers with various level of experience choose making-do at similar rate. In Chinese culture obedience and consistency is usually encouraged. While in the U.S., managers with 5 years or more experience choose making-do more often although there is a slight decrease in making-do choice for the group with 10 years or more experience. Also, results revealed that the biggest different in choosing making-do was observed in the group with 5-10 years of experience (62.7\% in China and $82.1 \%$ in the U.S.). 


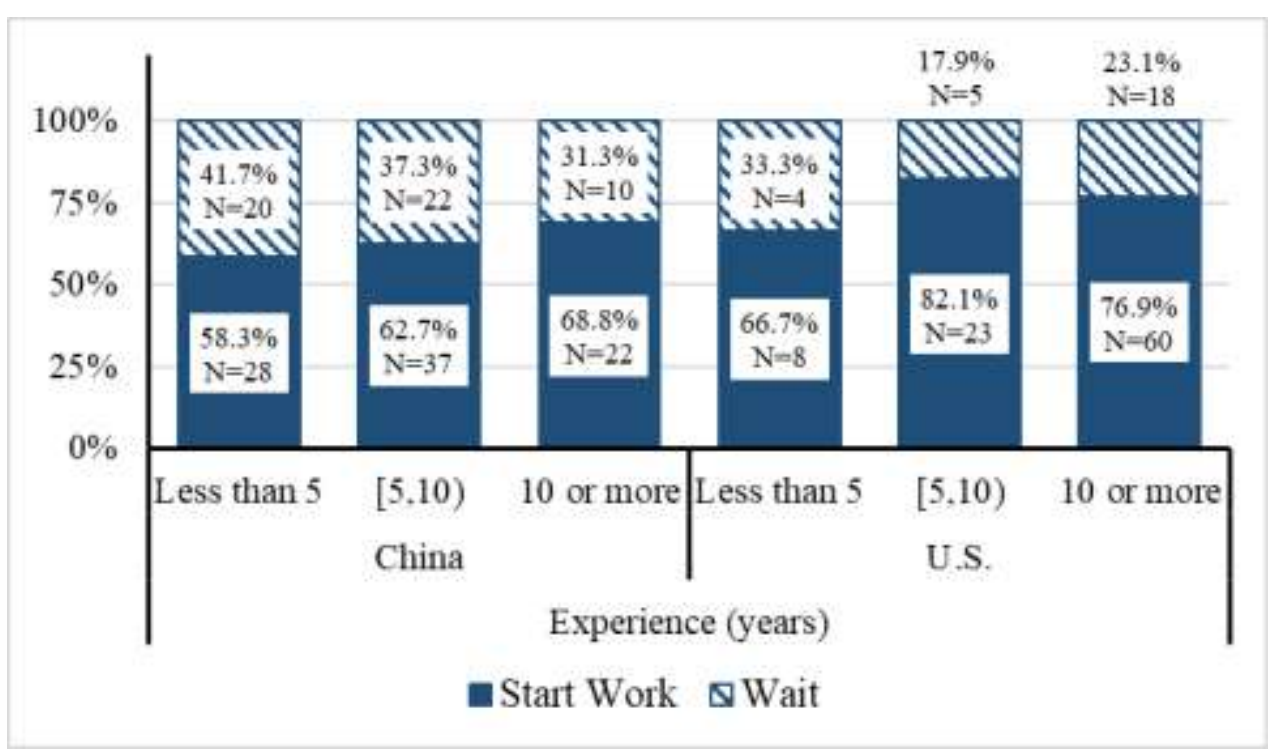

Figure 2: Making-do preference by years of work experience

\section{H-3: There is no association between making-do decision preferences and managers' responsibility levels.}

All usable responses were classified into three groups based on their position level: (1) crew/labor, (2) middle-level managers (foremen and superintendents), and (3) high-level managers (project managers). Chi-square test was conducted for each country and combined. None of the chi-squares were statistically significant, meaning that the null hypothesis is true: making-do decision and position levels are independent (not related). Figure 3 shows that in China, there is high level consistency in making-do selection percentage for all three level of managers, at $37.8 \%, 36.4 \%$, and $35.7 \%$ respectively. The culture emphasize authority from higher-level commanders. Frequently asking for directions, following directions, are mimic supervisor's strategies are often encouraged and regarded as one of the criteria for promotion and career advancement. In the U.S., midlevel managers have much higher tendency choosing making-do than other level managers. 


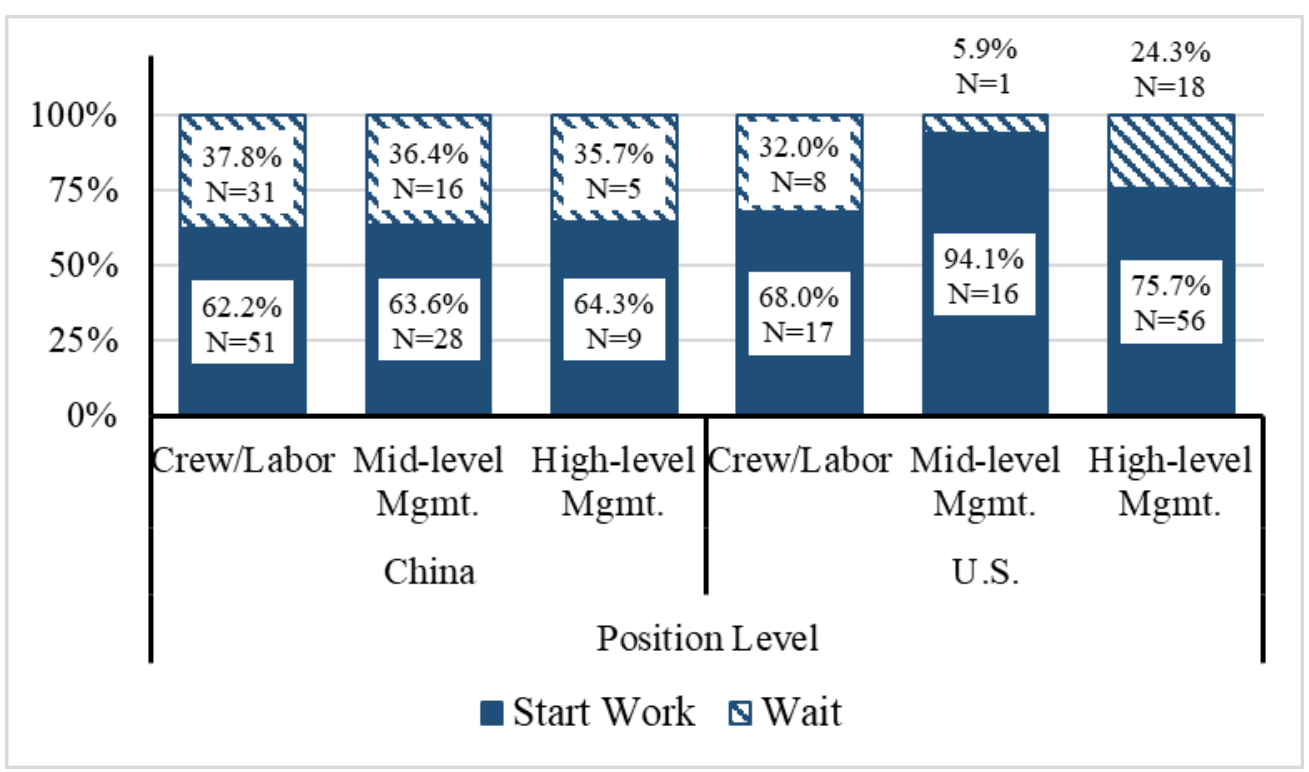

Figure 3: Percent of people start work or wait based on their position level

\section{H-4: Project managers with different making-do preferences experience the same amount of task starting time (and duration) variation.}

The average amount of starting time and duration variation (hours/week) experienced by the respondents due to the lack of readiness in the eight defined prerequisite categories were calculated (Table 2). The Mann-Whitney U test was performed using IBM SPSS Statistics V25 to examine the differences in the perceived amount of task starting time and duration variation for the making-do and none making-do group.

The Mann-Whitney $U$ test is a nonparametric test that compares the central locations of two population with similar-shape distributions (not necessarily normal) when there are two independent random samples drawn from these populations (i.e. people who start work and people who wait). Instead of comparing the raw data directly, the Mann-Whitney U test compares the ranked data (Newbold et al., 2012; Norušis 2012). Observations from the two samples are combined and ranked on the ascending order. If there are tied observations, the average of ranks is assigned to all of them. The Mann-Whitney $U$ null hypothesis is that there is no difference in terms of task starting time and duration variation for the making-do and none making-do groups. In order to test this null hypothesis, the MannWhitney U statistic were calculated using the following formulas (Newbold et al., 2012):

$$
\begin{gathered}
U=n_{1} n_{2}+\frac{n_{1}\left(n_{1}+1\right)}{2}-R_{1} \\
E(U)=\mu_{U}=\frac{n_{1} n_{2}}{2} \\
\operatorname{Var}(U)=\sigma_{U}^{2}=\frac{n_{1} n_{2}\left(n_{1}+n_{2}+1\right)}{12}
\end{gathered}
$$




$$
Z=\frac{U-\mu_{U}}{\sigma_{U}}
$$

where $n_{1}$ and $n_{2}=$ size of the "making-do" and "none making-do" groups; $R_{1}=$ the sum of the ranks of the "making-do" group; $\sigma^{2} \mathrm{U}=$ the variance of the Mann-Whitney U; and $\mu_{U}=$ the mean of the Mann-Whitney U. After calculating the $Z$ value, decision was made to whether reject or accept the null hypothesis considering significance level of $\alpha=0.05$.

Table 2: Average experienced task starting time and duration variation (h/week)

\begin{tabular}{cccccccccc}
\hline $\begin{array}{c}\text { Prerequisite } \\
\text { Categories }\end{array}$ & \multicolumn{4}{c}{ China } & \multicolumn{3}{c}{ U.S. } \\
\cline { 2 - 9 } & $\begin{array}{c}\text { Avg. Starting } \\
\text { Time Var. } \\
\text { (h/week) }\end{array}$ & $\begin{array}{c}\text { Avg. Duration } \\
\text { Var. (h/week) }\end{array}$ & $\begin{array}{c}\text { Avg. Starting } \\
\text { Time Var. } \\
\text { (h/week) }\end{array}$ & $\begin{array}{c}\text { Avg. Duration } \\
\text { Var. (h/week) }\end{array}$ \\
\cline { 2 - 10 } & Start & Wait & Start & Wait & Start & Wait & Start & Wait \\
\cline { 2 - 11 } Prerequisite Work & 1.14 & 0.94 & 1.08 & 1.04 & $1.18^{*}$ & $1.53^{*}$ & 0.92 & 0.80 \\
Design \& Specs & 0.87 & 0.70 & 1.13 & 0.86 & $0.75^{*}$ & $1.71^{*}$ & $0.87^{*}$ & $1.41^{*}$ \\
Labor & 0.87 & 0.94 & $1.23^{*}$ & $0.91^{*}$ & $0.52^{*}$ & $0.72^{*}$ & $0.76^{*}$ & $1.11^{*}$ \\
Equipment & 0.44 & 0.33 & $0.53^{*}$ & $0.35^{*}$ & $0.32^{*}$ & $0.56^{*}$ & $0.31^{*}$ & $0.44^{*}$ \\
Material & 0.63 & 0.50 & $0.69^{*}$ & $0.40^{*}$ & $0.67^{*}$ & $1.32^{*}$ & 0.73 & 0.79 \\
Layout \& Space & 0.74 & 0.50 & 0.70 & 0.65 & $0.72^{*}$ & $1.12^{*}$ & 0.72 & 0.92 \\
Information Flow & 0.61 & 0.54 & 0.87 & 0.78 & 0.69 & 0.90 & 0.75 & 0.88 \\
External Conditions & 0.78 & 0.80 & 1.04 & 0.82 & $0.65^{*}$ & $0.92^{*}$ & 0.99 & 1.20 \\
\hline
\end{tabular}

Table 2 shows average of task starting time and duration variation (h/week) experienced by the respondents in China and the U.S. Respondents' experienced variations were ranked in each of the eight precondition categories and arithmetic mean scores were calculated for China and the U.S. data separately. Mean scores are plotted in Figure 4 and Figure 5. The results of the Mann-Whitney $U$ test revealed there is a statistically significant difference (at $\alpha=0.05$ ) in experienced starting time (and duration) variation by people with different making-do preference due to the lack of readiness in seven of the eight precondition categories and therefore the null hypothesis is rejected.

These preconditions are indicated by an asterisk $\left(^{*}\right)$ next to the average variation in Table 2 and next to the prerequisite category labels in Figure 4 and Figure 5. Figure 4 shows how experience task starting time variation differs between making-do and none making-do respondents. There is not much difference experienced in task starting time delay due to the eight precondition categories for Chinese managers with different makingdo preferences (Figure 4a). But the U.S. managers who preferred to making-do have experienced significantly less task starting time variation due to lack of precondition readiness in all categories except "information flow" (Figure 4b). Figure 5a shows that respondents in China with making-do trait experienced higher amount of duration variation 
due to lack of readiness in "labor", "equipment", and "material" categories. There are also significant differences in the U.S. managers' experienced task duration variation in "design and specs", "labor", and "equipment" precondition categories for making-do and none making-do groups. Their experience is that forcing to start in the long run results in less task duration variation.

\section{CONCLUSIONS}

In order to understand how managers with different culture background choose making-do strategies differently and the rationale behind it, this research conducted two surveys in China and the U.S. Findings showed there was a significant difference in making-do decision preference for construction managers in China and in the U.S. However, there was no significant difference on making-do decision preference for managers with different levels of construction experience as well as with different responsibility levels. Results revealed that the U.S. managers who preferred making-do, experienced lower amount of task starting time and duration variation due to the lack of precondition readiness. On the

other hand, Chinese managers who preferred making-do, experienced higher amount of duration variation due to lack of readiness in labor, equipment, and material categories. This is one reason why in China fewer making-do decisions are made because Chinese managers have experienced more making-do wastes in terms of task duration variation. Interviews with five Chinese project managers indicated that obedience and constantly checking labor, equipment, and materials availabilities are emphasized in the culture and management practices. These contribute to the differences of making-do in Figure 5.

\section{LIMITATIONS AND FUTURE RESEARCH}

Survey in China was only conducted in one province, while the survey in the U.S. was nationwide. However, ShanDong province is the second most populous province and has the third highest GDP in China in 2017. Therefore, the results are useful and beneficial for managers. Future research can perform more in-depth analysis to find to what extend managers' experience of variation in the past contributes to their making-do decision for the future. 


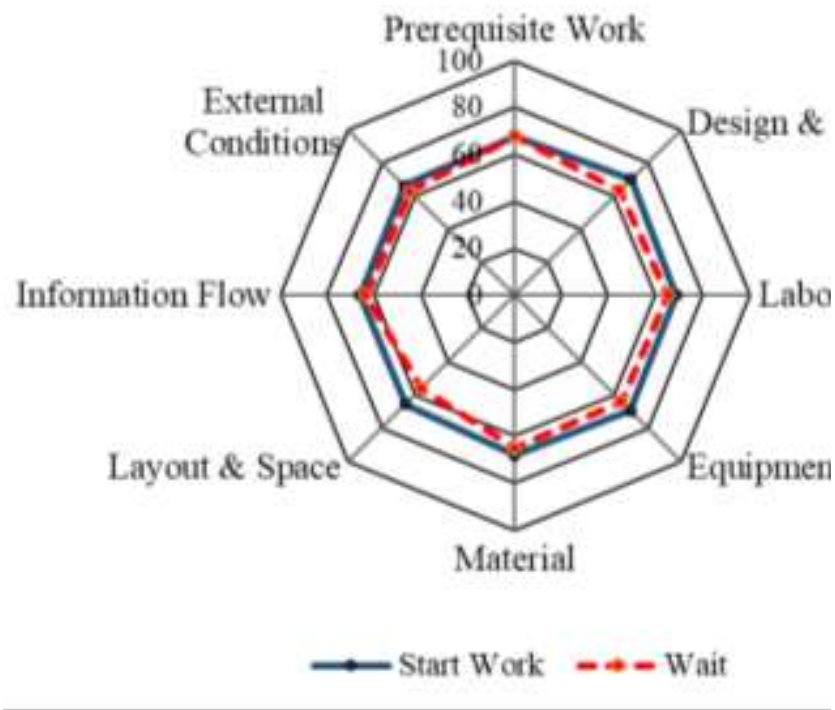

(a) China

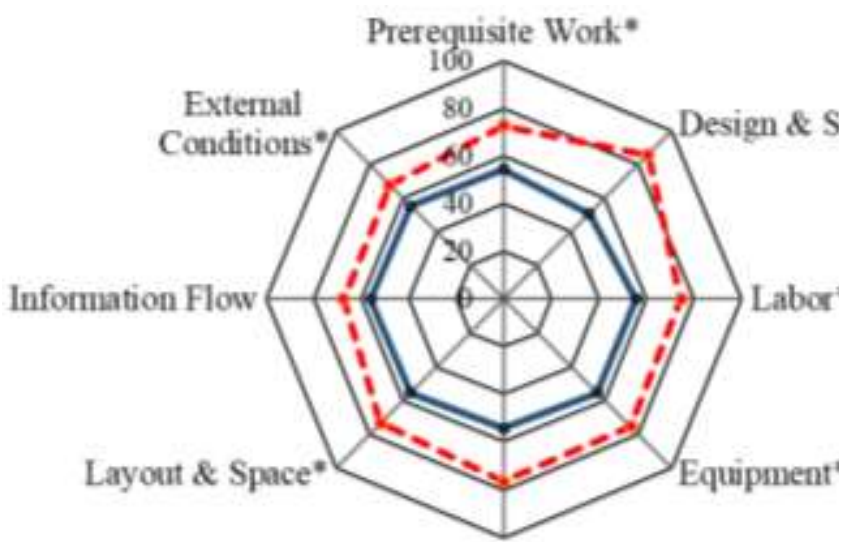

Material*

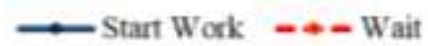

(b) U.S.

Figure 4: Task starting time variation profiles experienced by construction practitioners

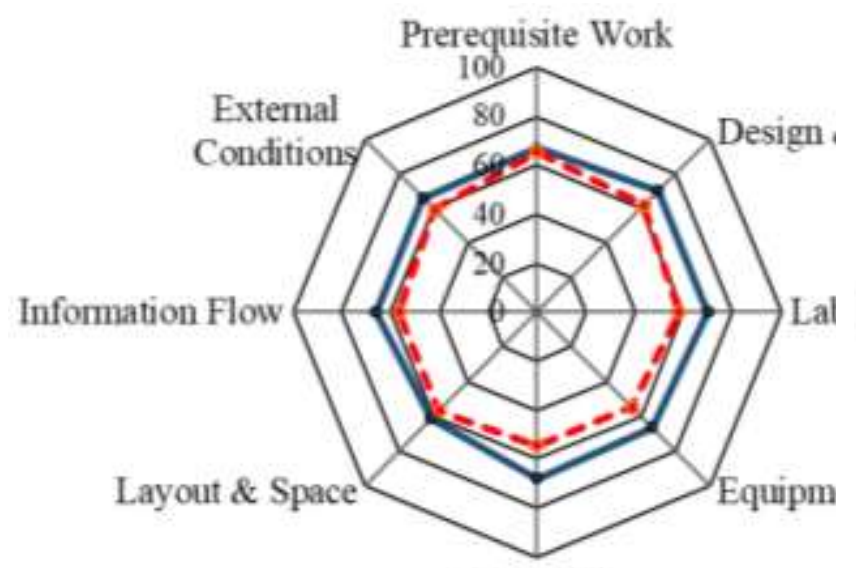

Material*

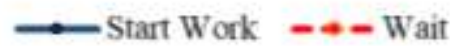

(a) China

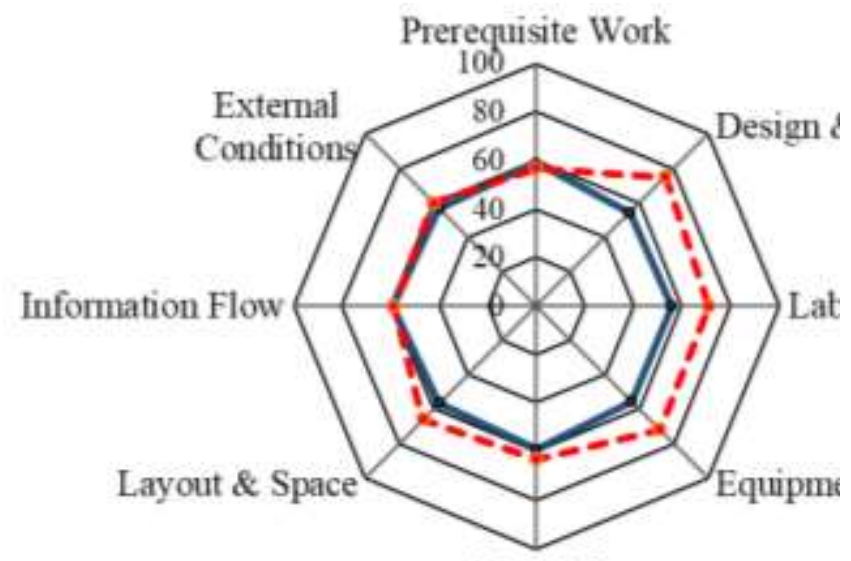

Material

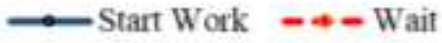

(b) U.S.

Figure 5: Task duration variation profiles experienced by construction practitioners 


\section{REFERENCES}

Bølviken, T. \& Koskela, L. (2016). "Why Hasn't Waste Reduction Conquered Construction?" Proc. 24 $4^{\text {th }}$ Annual Conference of the International Group for Lean Construction, Boston, USA.

Cunha, M.P. (2004) Bricolage in Organizations. Instituto Nova Fórum. Universidade Nova de Lisboa.

Formoso, C.T., Sommer, L., Koskela, L.J., \& Isatto, E.L. (2011). "An exploratory study on the measurement and analysis of making-do in construction sites." Proc. $19^{\text {th }}$ Ann. Conf. of the Int'l Group for Lean Construction, Lima, Peru, 236-246.

Iglewicz, B., and Hoaglin, D. C. (1993). How to detect and handle outliers. ASQC Quality Press, Milwaukee, WI, USA.

Koskela, L. (2000). An exploration towards a production theory and its application to construction. VTT Technical Research Centre of Finland.

Koskela, L. (2004). "Making-Do - The Eighth Category of Waste." Proc., 12th Ann. Conf. of the Int'l Group for Lean Construction. Helsingør, Denmark, 1-10.

Koskela, L., Bølviken, T. \& Rooke, J. (2013). "Which are the wastes of construction?"

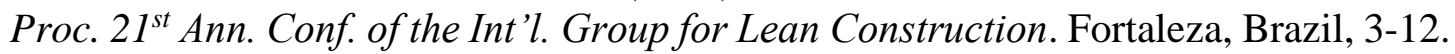

Neve, H. H., \& Wandahl, S. (2018). "Towards identifying making-Do as lead Waste in Refurbishment projects." $26^{\text {th }}$ Annual Conference of the International Group for Lean Construction, Chennai, India, 1354-1364.

Newbold, P., Carlson, W., Thorne, B.M. (2012). Statistics for Business and Economics. Pearson, UK.

Norušis, M. J. (2012). IBM SPSS statistics 19 statistical procedures companion. Prentice Hall, NJ, USA.

Pikas, E., Sacks, R., and Priven, V. (2012). "Go or no-go decisions at the construction workface: Uncertainty, perceptions of readiness, making ready and making-do." Proc., $20^{\text {th }}$ Annual Conf. of the Int. Group for Lean Construction, San Diego State Univ., San Diego, 431-440.

Wambeke, B. W., Hsiang, S. M., \& Liu, M. (2011). "Causes of variation in construction project task starting times and duration." Journal of construction engineering and management, 137(9), 663-677. 